\title{
Event-based runoff and sediment yield dynamics and controls in the sub-humid headwaters of the Blue Nile, Ethiopia
}

\author{
Habtamu Assaye Deffersha ${ }^{1}$, Jan Nyssen $^{2}$, Jean Poesen ${ }^{3}$, Hanibal Lemma ${ }^{4}$, Derege \\ Meshesha $^{1}$, Alemayehu Wassie ${ }^{1}$, Enyew Tsegaye ${ }^{1}$, Deribew Fentie ${ }^{1}$, and Amaury Frankl ${ }^{2}$ \\ ${ }^{1}$ Bahir Dar University College of Agriculture and Environmental Sciences \\ ${ }^{2}$ Ghent University Faculty of Sciences \\ ${ }^{3} \mathrm{KU}$ Leuven \\ ${ }^{4}$ Bahir Dar University Institute of Technology
}

April 7, 2021

\begin{abstract}
Land degradation due to soil erosion presents a challenge for sustainable development. We investigated the impact of land use type and land management practices on runoff and sediment yield dynamics in the northwestern highlands of Ethiopia. The study area included 14 zero-order catchments with a surface area ranging from $324 \mathrm{~m} 2$ to $1715 \mathrm{~m} 2$. V-notch weirs produced from plastic jars were introduced as measuring alternatives that met local constraints. Runoff depth at the weir was registered at 5-min intervals during two rainy seasons in 2018 and 2019. Rainfall was measured using tipping-bucket rain gauges. Runoff samples were collected in 1-L bottles and suspended sediment concentration (SSC) was determined. The mean event runoff coefficient ranged from $3 \%$ for forests to $56 \%$ for badlands. Similarly, the mean annual sediment yield (SY) was lowest for forests (0.8 Mg ha-1 yr-1) and highest for badlands (43.4 Mg ha-1 yr-1), with significant differences among land use types (14.8 Mg ha-1 yr-1 in cropland, $5.7 \mathrm{Mg}$ ha-1 yr-1 in grazing land, and $2.9 \mathrm{Mg}$ ha-1 yr-1 in plantations). Soil organic matter (SOM) reduced runoff and SY, necessitating the consideration of agronomic and land management practices that enhance SOM. Annual SY decreased exponentially with the rock fragment cover (RFC). In fields where RFC was less than $20 \%$, collecting rock fragments for installing stone bunds resulted in a net increase in SY. Rehabilitating badlands and enhancing SOM content in croplands can substantially reduce catchment SY and, hence considerably contribute to the sustainability of this type of environment.
\end{abstract}

\section{Hosted file}

Manuscript.pdf available at https://authorea.com/users/406263/articles/516984-event-basedrunoff-and-sediment-yield-dynamics-and-controls-in-the-sub-humid-headwaters-of-the-bluenile-ethiopia 